\title{
Bromine catalyst for the methane to methyl bisulfate reaction
}

\author{
Beata Michalkiewicz*, Sylwia Balcer \\ West Pomeranian University of Technology, Szczecin, ul. Pułaskiego 10, 70-322 Szczecin, Poland \\ "Corresponding author: e-mail: beata.michalkiewicz@zut.edu.pl
}

\begin{abstract}
A catalytic system $\mathrm{KBr}$ - oleum is effective at catalyzing the selective oxidation of methane to methanol via. methyl bisulfate. The influences of methane pressure, sulfur trioxide and temperature on turnover frequency were investigated.
\end{abstract}

Keywords: methane, methyl bisulfate, methanol, $\mathrm{KBr}$

\section{INTRODUCTION}

Methane is currently converted to commercially more useful materials by multi -step and/or high temperature processes. The selective catalytic functionalization of methane to value added products is highly desirable ${ }^{1}$. Recently, several reports of alkane $\mathrm{CH}$ activation by homogeneous catalytic systems have been reported. Usually metal cations or cationic metal complexes were used as catalysts ${ }^{2-9}$. There are some investigations on iodine complex also ${ }^{10,11}$.

The catalytic process involves the contacting of methane with acid and catalyst and oxidizing agent. Methane is oxidized according to equation (1).

$\mathrm{CH}_{4}+\mathrm{H}_{2} \mathrm{SO}_{4}+\mathrm{SO}_{3} \rightarrow \mathrm{CH}_{3} \mathrm{OSO}_{3} \mathrm{H}+\mathrm{H}_{2} \mathrm{O}+\mathrm{SO}_{2}$

The obtained methyl oxy-ester of the acid is relatively inert to further oxidation under reaction conditions. Water reacts rapidly with sulfur trioxide according to equation (2).

$\mathrm{H}_{2} \mathrm{O}+\mathrm{SO}_{3} \rightarrow \mathrm{H}_{2} \mathrm{SO}_{4}$

Net reaction:

$\mathrm{CH}_{4}+2 \mathrm{SO}_{3} \rightarrow \mathrm{CH}_{3} \mathrm{OSO}_{3} \mathrm{H}+\mathrm{SO}_{2}$

Methyl bisulfate may then be converted to methanol: $\mathrm{CH}_{3} \mathrm{OSO}_{3} \mathrm{H}+\mathrm{H}_{2} \mathrm{O} \rightarrow \mathrm{CH}_{3} \mathrm{OH}+\mathrm{H}_{2} \mathrm{SO}_{4}$

Herein we report that $0.017 \mathrm{M} \mathrm{KBr}$ dissolved in sulfuric acid containing $\mathrm{SO}_{3}(6-25 \mathrm{wt} \%)$ generates stable, active species that catalyzes the functionalization of methane (3.4-6.2 MPa) to methyl bisulfate at $110-180^{\circ} \mathrm{C}$. To the best of our knowledge only two perfunctory notifications about $\mathrm{KBr}$ can be found $\mathrm{d}^{\mathbf{1 1 , 1 2}}$ and this is the first extensive report about oleum concentration, methane pressure and temperature influence on the methane functionalization by $\mathrm{KBr}$ catalyst.

\section{EXPERIMENTAL}

The reaction between methane, sulfuric acid, and sulfur trioxide was performed in a batch reactor (autoclave with stirrer). The effective volume of the reactor was $0.25 \mathrm{dm}^{3}$ for the gas and liquid together. The $0.10 \mathrm{dm}^{3}$ of oleum was poured into autoclave. Then the $\mathrm{KBr}$ working as a catalyst was added. The air was removed by passing through the methane. Thereafter the reactor was heated and pressurized with the methane. After reaction time the reactor was cooled down to room temperature by water.

The gasses were analyzed by GC equipped with a thermal conductivity detector. Hydrogen was used as the carrier gas. The HaySep T and Molecular Sieve 5A columns were applied. The qualitative analysis of the liquid reaction mixture was performed by ${ }^{13} \mathrm{C}$ NMR.
It is not easy to analyze quantitatively the ester. So the $\mathrm{CH}_{3} \mathrm{OSO}_{3} \mathrm{H}$ was first hydrolyzed to methanol by the water and then analyzed quantitatively by GC on HaySep T column.

\section{RESULTS AND DISCUSSION}

Use ${ }^{13} \mathrm{C}$ NMR analyses showed that methyl bisulfate was the only liquid-phase product containing carbon. Contrary to the Periana group ${ }^{11}$ the poly-halogenated methanes were not observed. The traces of $\mathrm{CO}_{2}$ were detected in the gas phase (below $1 \%$ yield based on methane added). Any other containing carbon products have not been found.

$\mathrm{KBr}$ was required for the reaction as no methyl bisulfate is formed in the absence of the added catalyst. When the concentration of the catalyst was lower than $0.017 \mathrm{M}$ the decreasing of the $\mathrm{KBr}$ amount decreased the rate of the methane to methyl bisulfate oxidation. The increasing of $\mathrm{KBr}$ concentration above $0.017 \mathrm{M}$ did not influence the methane conversion. This is most probable that the solubility of $\mathrm{KBr}$ in oleum at the given conditions can be found according to this point. A similar phenomenon was observed by Gang et al. ${ }^{10}$ and by us in our earlier work ${ }^{12}$.

Contrary to the Periana et al. ${ }^{11}$ we have found that bromine can be an active and stable catalyst in methane oxidation in oleum. The ester concentration increased with the time indicating that the catalyst was not deactivated during the reaction.

The values of turnover frequencies (TOF) are reproducible. The typical error does not exceed $10 \%$. The mean values of TOF vs. pressure, sulfur trioxide concentration and temperature are presented in Figures 1-3. The maximum value of the turnover numbers was about 71 and was increased with the time.

On the basis of Figures 1-3, we can state that the reaction rate strongly depends on methane pressure, sulfur trioxide concentration and temperature. One can assume the first order dependence on both methane and sulfur trioxide. But more investigation is needed to reveal the nature of the process.

On the basis of Figure 3 it was found that TOF follow an exponential temperature dependence when the reaction was stopped after 2 hours. If the reaction time was $22 \mathrm{~h}$ and longer only up to $140^{\circ} \mathrm{C}$ exponential dependence was observed. The low methane pressure or concentration of sulfur trioxide can be the reason. The reaction took place if methane pressure is higher than 3.4 MPa and concentration of sulphur trioxide higher than 


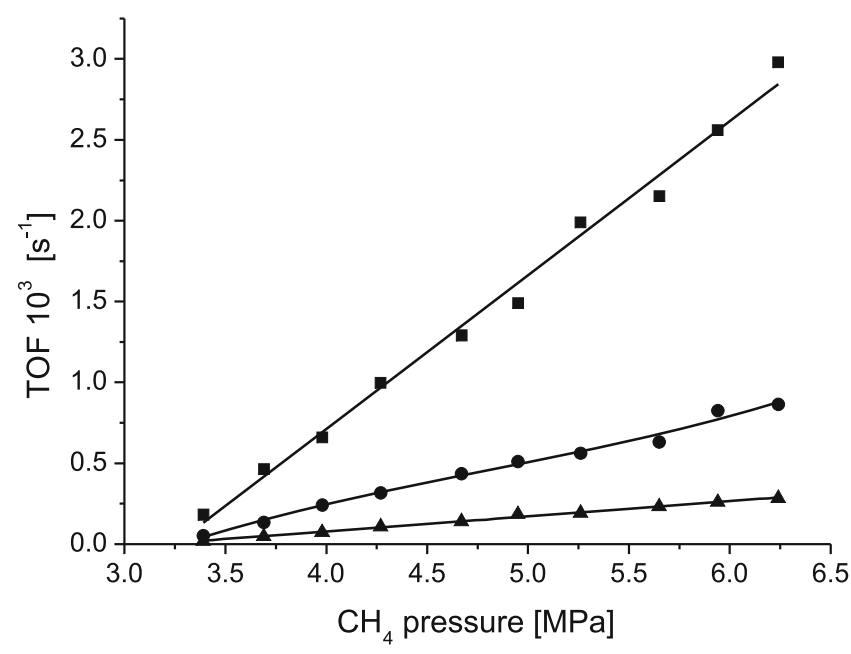

Figure 1. TOF vs. methane pressure, $\mathrm{C}_{\mathrm{SO} 3}=25 \mathrm{wt} \%, \mathrm{t}=160^{\circ} \mathrm{C}$, time: $\boldsymbol{\square}-2 \mathrm{~h}, \boldsymbol{\bullet}-22 \mathrm{~h}, \boldsymbol{\Delta}-70 \mathrm{~h}$

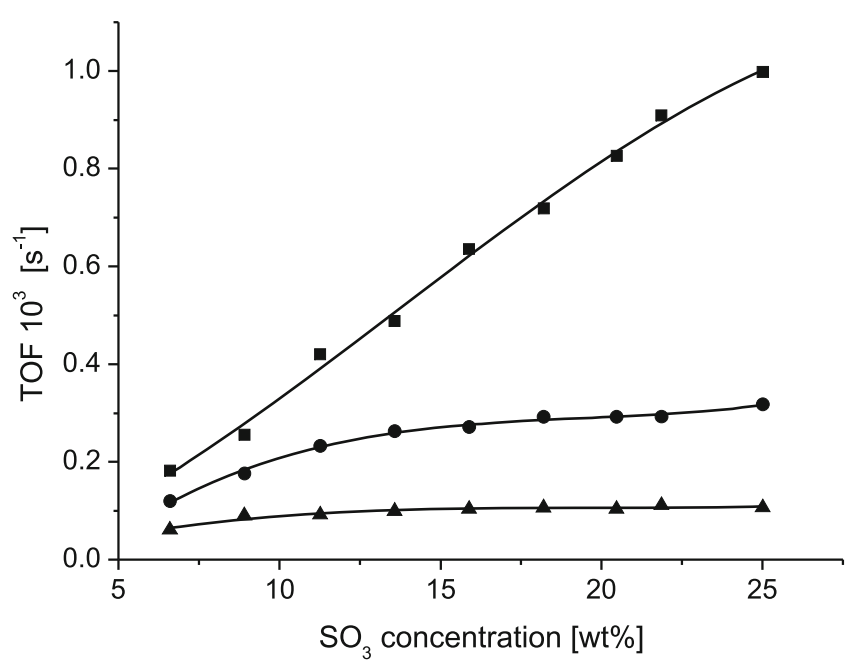

Figure 2. TOF vs. sulfur trioxide concentration, $\mathrm{p}_{\mathrm{CH} 4}=4.27$ $\mathrm{MPa}, \mathrm{t}=160^{\circ} \mathrm{C}$, time: $\boldsymbol{\square}-2 \mathrm{~h}, \mathbf{0}-22 \mathrm{~h}, \boldsymbol{\Delta}-70 \mathrm{~h}$

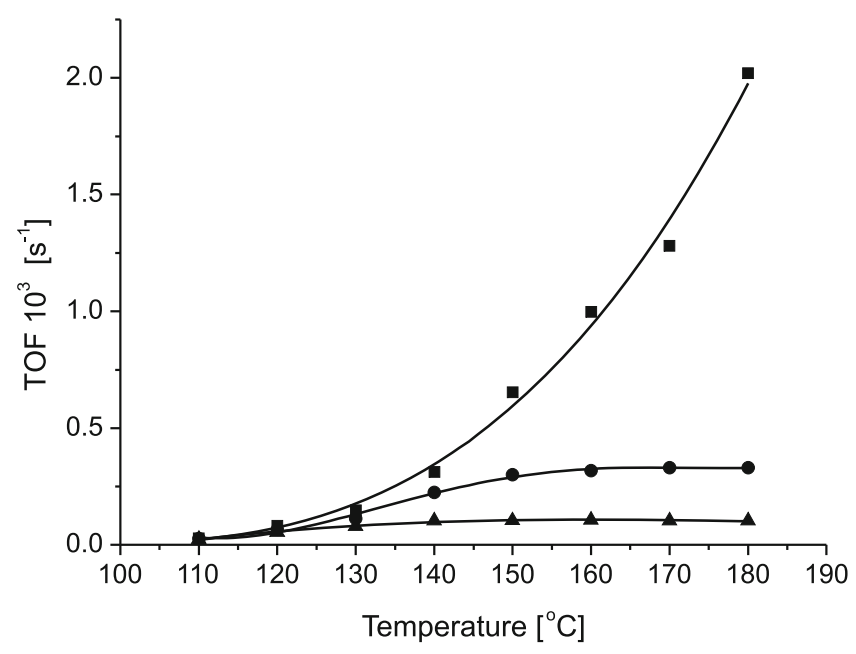

Figure 3. TOF vs. temperature, $\mathrm{C}_{\mathrm{SO}_{3}}=25 \mathrm{wt} \%, \mathrm{t} \mathrm{p}_{\mathrm{CH} 4},=4.27$ MPa, time: $-2 \mathrm{~h}, \mathbf{0}-22 \mathrm{~h}, \boldsymbol{\Delta}-70 \mathrm{~h}$

$6.6 \mathrm{wt} \%$. The reaction stopped when these values fall. Raising the initial methane pressure and concentration of sulfur trioxide increase methyl bisulfate yield. The methyl bisulfate yield using $\mathrm{KBr}$ as the catalyst equal to $50 \%$ was achieved at initial methane pressure equal to $6.24 \mathrm{MPa}$ and sulphur trioxide concentration $25 \mathrm{wt} \%$. It is worth to notice that at this initial conditions, when methyl bisulfate yield arise $50 \%$, the methane pressure falls up to 3.14 and sulphur trioxide concentration up to $12.5 \mathrm{wt} \%$. So the low pressure is the reason that the reaction stopped. These limitation are the reason that Periana et al. ${ }^{11}$ stated bromine not active and stable catalyst. This authors performed the methane oxidation at $3.45 \mathrm{MPa}$ and $2.5 \mathrm{wt} \% \mathrm{SO}_{3}$. They achieved $10 \%$ ester yield. They did not give TOF for reaction catalyzed by $\mathrm{Br}_{2}$ because that catalyst seemed to be unstable. We have found that if methane pressure and concentration of sulfur trioxide were high enough the reaction took place long time and $\mathrm{KBr}$ catalyst is active long time.

In spite of very low $\mathrm{SO}_{3}$ concentration Periana et al. ${ }^{11}$ observed methyl bisulfate and extensive poly-halogenated methanes in the products. The experimental procedure was similar to ours but the reactor was smaller. This processes involves mass transfer between gas and liquid phase with consecutive, or parallel, reversible, or irreversible reactions. This reaction system is very complicated and different routes can occur. Besides temperature, pressure and $\mathrm{SO}_{3}$ concentration the overall reactor volume, gas and liquid phase volume, surface of the liquid can play an important role.

It has been known for many years that iodine dissolves in strongly oxidizing solvents such as oleum give diiodine cation $\mathrm{I}_{2}^{+}$. It has been reported that the related cations of bromine and chlorine are not stable in oleum ${ }^{13}$. The ionization energies of $\mathrm{Br}_{2}$ and $\mathrm{Cl}_{2}$, whilst greater than that for $\mathrm{I}_{2}$ are nevertheless smaller than for $\mathrm{O}_{2}$, which can likewise be oxidized to $\mathrm{O}^{2+}$. Compounds of the bright-red cationic species $\mathrm{Br}^{2+}$ are well established ${ }^{14}$. It is very probable that in a strong oxidizing agent such as oleum $\mathrm{Br}^{2+}$ are stable and catalyze methane oxidation according to the reaction (5):

$2 \mathrm{Br}^{-}+6 \mathrm{SO}_{3}+1.5 \mathrm{H}_{2} \mathrm{SO}_{4} \rightarrow \mathrm{Br}_{2}^{+}+3 \mathrm{HS}_{2} \mathrm{O}_{7}^{-}+1.5 \mathrm{SO}_{2}(5)$

On the basis of Figure 2 we can assume that the concentration of $\mathrm{SO}_{3}$ is a key to generate bromine cation but investigation should be developed. Below $6 \mathrm{wt} \%$ methyl bisulfate was not observed.

\section{CONCLUSION}

We have developed a new highly selective low temperature catalyst $-\mathrm{KBr}$ for homogeneous methane to methyl ester and than methanol conversion. Sulfur trioxide as oxidant and sulfuric acid as esterification agent were used. The increasing temperature, sulfur trioxide concentration or methane pressure result in the TOF grow. Further investigations on the mechanism and kinetics of the reaction are required.

\section{LITERATURE CITED}

1. Mukhopadhyay, S. \& Bell, A.T. (2003) Direct catalytic sulfonation of methane with $\mathrm{SO} 2$ to methanesulfonic acid (MSA) in the presence of molecular $\mathrm{O}_{2}$. Chem. Commun. 1590-1591. DOI: 10.1039/b303561a.

2. Kao, L-C, Hutson, A.C. \& Sen, A. (1991) Low temperature, palladium(II)-catalyzed, solution-phase oxidation of methane to methanol derivative. J. Am. Chem. Soc. 113, 700-701. DOI: 10.1021/ja00002a063.

3. Periana, R.A.,. Taube, D.J, Evitt, E.R., Löffle,r D.G., Wentrcek, P.R, Voss, G. \& Masuda, T. (1993) A Mercury-Catalyzed, High-Yield System for the Oxidation of Methane to Methanol. Science 259, 340.-343. DOI: 10.1126/science.280.5363.493f. 
4. Sen, A., Benvenuto, M.A., Lin, M.,. Hutson, A.C. \& Basickes, N. (1994) Activations of Methane and Ethane and Their Selective Oxidation to the Alcohols in Protic Media. $J$. Am. Chem. Soc. 116, 998-1003. DOI: 10.1021/ja00082a022.

5. Periana, R.A., Taube, D.J., Gamble, S., Taube, H., Satoh, T. \& Fujii, H. (1998) Platinum Catalysts for the High-Yield Oxidation of Methane to a Methanol Derivative. Science 280, 560-564. DOI: 10.1126/science.280.5363.560.

6. Gang, X., Birch, H., Zhu, Y., Hjuler, H.A. \& Bjerrum, N.J. (2000) Direct Oxidation of Methane to Methanol by Mercuric Sulfate Catalyst. J. Catal. 196, 287-292. DOI: $10.1006 /$ jcat.2000.3051.

7. Michalkiewicz, B., Kałucki, K. \& Sośnicki, J.G. (2003) Catalytic system containing metallic palladium in the process of methane partial oxidation. J. Catal. 215, 14-19. DOI: 10.1016/S0021-9517(02)00088-X.

8. Michalkiewicz, B. (2006) The kinetics of homogeneous catalytic methane oxidation. Appl. Catal. A. 307, 270-274. DOI: 10.1016/j.apcata.2006.04.006.

9. Cheng, J., Li, Z., Haught, M. \& Tang, Y. (2006) Direct methane conversion to methanol by ionic liquid-dissolved platinum catalysts. Chem. Commun. 4617-4619. DOI: $10.1039 / \mathrm{b} 610328 \mathrm{f}$.

10. Gang, X., Zhu, Y., Birch, H., Aage, H., Hjuler, A. \& Bjerrum, N. (2004) Iodine as catalyst for the direct oxidation of methane to methyl sulfates in oleum. Appl. Catal. A. 261, 91-98. DOI: 10.1016/j.apcata.2003.10.039.

11. Periana, R. A., Mirinov, O., Taube, D. J. \& Gamble, S. (2002) High yield conversion of methane to methyl bisulfate catalyzed by iodine cations. Chem. Commun. 2376-2377. DOI: 10.1039/B205366G.

12. Jarosińska, M., Lubkowski, K., Sośnicki, J.G. \& Michalkiewicz, B. (2008) Application of Halogens as Catalysts of CH4 Esterification. Catal. Lett. 126, 407-412. DOI 10.1007/s10562-008-9645-8.

13. Gillespie, R.J. \& Morton, M.J., (1971) Halogen and interhalogen cations. Quart. Rev. 25, 553-559 DOI: 10.1039/ QR9712500553.

14. Greenwood, N.N., Earnshaw, A. (1987) Chemistry of the Elements, Butterworth-Heinemann Oxford and references therein. 